\title{
Sustained Yield in Alberta ${ }^{1}$
}

\author{
by
}

\author{
F.W. McDougall ${ }^{2}$
}

\begin{abstract}
The concept of sustained yield is examined with particular reference to the sustained yield concept as it is required to be applied by Alberta law and through the requirements of the regulations, timber quota certificates and forest management agreements. The adequacy of the sustained yield vision in Alberta is discussed. Actual forest management practices are examined in the light of the Alberta requirements. Some shortcomings are noted, and a number of serious problems are described. However, the author concludes that a dedicated and successful effort is being made, and the most important problems are being tackled vigorously, to the limit of the resources available. More funding is urgently needed to support cleaning and tending operations in young coniferous stands, particularly if governments continue to refuse to allow low cost brush control through the use of ground applications of federally approved biodegradable and non-toxic herbicides, such as glyphosate.
\end{abstract}

\section{Résumé}

Le concept de rendement soutenu est étudié sous l'angle particulier du concept de rendement soutenu tel qu'il doit être appliqué selon la législation albertaine et selon les exigences des réglements, des allocations de matière ligneuse et les accords d'aménagement forestier. L'adéquation de la vision du rendement soutenu en Alberta est discutée. Les pratiques actuelles d'aménagement forestier sont examiné à la lumière des besoins en Alberta. Quelques défauts sont relevés, et un certain nombre de problèmes sérieux sont décrits. Toutefois, l'auteur en vient à la conclusion qu'un effort déterminé et couronné de succès est en voie de réalisation, et que les plus importants problèmes ont été cernés adéquatement, à la limite des ressources disponibles. II existe un besoin urgent de financement pour supporter les opérations de nettoiement et d'éducation des jeunes peuplements de conifères, particulièrement si les gouvernements persistent d'interdire le contrôle à faible coût des broussailles au moyen d'ap. plications terrestres de phytocides biodégradables et non-toxiques approuvés par le fédéral, tel le glyphosate.

\section{Sustained Yield - What is the Vision?}

There are a number of definitions of sustained yield, because it is a concept that can be applied in a number of ways. The Society of American Foresters defines sustained yield (management) as "the yield that a forest can produce continuously at a given intensity of management". They note that sustained yield management "therefore implies continuous production so planned as to achieve at the earliest practical time a balance between increment and cutting".

In the second edition of his text "Forest Management: Regulation and Valuation", K.P. Davis points out that sustained productivity "may be thought of in two senses: as continuity of growth and continuity of yield or harvest"'. He goes on to point out the term is most commonly used to mean continuity of harvest, even though, "current harvest does not necessarily equal current growth, although in the long run and on the average it must". In his book he applies the term to mean continuity of harvest.

The Forestry Handbook for British Columbia defines sustained yield "as the yield that a forest can produce continuously at a given intensity of management. Sustained-yield management therefore implies continuous production, so planned as to achieve at the earliest practical time a balance between increment and cutting."

\footnotetext{
Paper given in Panel on Sustained Yield at the CIF Annual Meeting at Kananaskis Village,

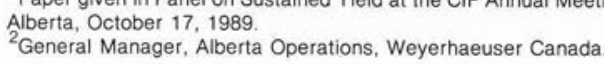

Some key questions to be asked about any forest that is to be managed under sustained yield are:

- Over what period of time will harvest differ from growth?

- What degree of harvest fluctuation, and growth fluctuations is permissable?

- What is the desired age-class structure and stand composition and how long will it take to attain these?

- How long will it be before the forest is brought to a "balanced" state?

In any application where these questions are not clearly answered, the sustained yield vision will be cloudy indeed.

\section{What is the Vision of Sustained Yield in Alberta}

In Alberta, the Forests Act states that the Minister may enter into a forest management agreement with any person "to enable that person to enter on forest land for the purpose of establishing, growing and harvesting timber in a manner designed to provide a perpetual sustained yield".

The Minister is authorized, by Section 14 of the Forests Act, to divide forest land into forest management units and determine the annual allowable cut of timber with respect to each forest management unit. Section 19 of the Act goes on to state that " In order to attain within a forest management unit a proper balance between growth and depletion of timber, the Minister may from time to time fix or alter the volume of timber that may be harvested or the amount of forest land 
on which the timber may be harvested by a timber quota holder during each quadrant".

Forest management agreements in Alberta call for " the perpetual sustained yield of timber" or for "a perpetual supply of benefits and products while maintaining a forest environment of high quality". All of the forest management agreements require that the forest management areas be managed "for establishing, growing and harvesting trees on a perpetual sustained yield basis for a defined period of time..." They further require forest management that shall "follow sound forestry practices with the purpose of achieving and maintaining a perpetual sustained timber yield from the productive forest land while not diminishing the productivity of the land..."

Additionally, all forest management agreements require that forest management plans be submitted for the Minister's approval that will "describe the methods it will follow in managing the forest management area on a sustained yield basis for a period equivalent to one approved full rotation...". The plans must include yield projections for a period equivalent to at least one full rotation, and harvest schedules for the duration of the agreement (20 years).

Clearly, sustained yield is firmly entrenched in Alberta Legislation at least to the extent that there must be continuity of growth, on a perpetual basis, without diminishing the productivity of the land. Furthermore, it is a requirement to develop a management plan that shows how the yield will be sustained for "one approved full rotation".

In fact, the forest management agreements, timber quotas and timber management regulations require the application of a comprehensive forest management program in Alberta. The entire program is based on achieving a concept of sustained yield that incorporates the following policy objectives:

(a) Establishment of a secure land base for productive forests through a comprehensive integrated resource planning program which gives full consideration to watershed, wildlife, recreation, agriculture, wilderness and other values when defining land to be managed for timber production.

(b) Restricting the annual fire loss to less than $1 / 10$ of $1 \%$ of the total forested area in each forest management area or unit. This objective requires a massive and expensive program but is essential to achieving sustained yield.

(c) Establishing allowable annual cuts for each forest management area or unit that are sustainable through a minimum of one entire rotation based on comprehensive forest management plans which consider stand age and condition as well as species composition, site and volume as determined from comprehensive forest inventories. Periodic recalculation of the AAC at a minimum 10-year interval is required to ensure the objective of sustained yield is being realized. AAC's are also recalculated to address catastrophic or land base losses as they occur.

(d) Full utilization of allowable annual cuts. Full utilization is required $(90 \%)$ and over-cutting is not allowed. Timber harvesting is not controlled annually but is tightly regulated within five-year "quadrants" on twenty-year quotas and forest management agreements.

(e) Salvage of fire-killed, infested and diseased timber must take precendence over the harvest of green timber. (f) Stringent protection of the forest environment and other resource values, such as water quality, wildlife, scenic values through the application of stringent timber harvesting ground rules and through the detailed review of annual operating plans.

(g) Prompt and progressive reforestation of all cut areas to tree species with a commercial value at least as great as those that were cut, with regulated stocking standards that insure that full stocking (in excess of $80 \%$ ) is achieved within eight years of cutting.

(h) Supplemental afforestation and intensive silviculture to achieve increased yields. This objective is encouraged through incentives and cost sharing.

\section{The Adequacy of the Alberta Vision}

Forest management in Alberta has emphasized the basics. Careful attention has been paid to: land base definition; effective forest protection, particularly against fire; prompt and complete reforestation; good forest inventories and comprehensive forest management planning to establish carefully considered allowable cuts that will be sustainable for a full rotation.

There are some blind spots in the Alberta vision. In order "to achieve at the earliest practical time a balance between increment and cutting", Alberta has set its annual allowable cuts at levels that can be sustained throughout one entire rotation, but they do not necessarily reflect a long-term "balance between increment and cutting". In cases where substantial volumes of old growth standing timber are utilized in excess of increment, it can result in an allowable annual cut that cannot be maintained in the second rotation based on forecast growth rates in the second forest. Such cutting in excess of the "long-range sustained yield average" is acceptable provided measures are taken now to increase growth in the second rotation. The problem is that such incremental measures are often not adequately specified in forest management plans giving rise to the risk of a reduction in the allowable annual cut in the second rotation.

Alberta has not placed a high priority on achieving age class balance in its forest management areas or units. Where there are serious age class imbalances, the preference has been to set the allowable cut at a level that can be sustained through the weakest age classes, with the help of any surplus old wood that might be carried to a very high harvest age to help cover the deficiency in the weaker age classes. Although this approach will gradually lessen age class imbalance, it does not eliminate the need for clear statements establishing schedules for achieving age class objectives. Nor has any attention been given to specifying silvicultural treatments to increase timber volumes in weak age classes. Thinning and stand cleaning are limited, and tend to take place on convenient sites, rather than as part of a program to meet a clear set of forest management objectives. There is no clearly stated time limit within which the forest is expected to be brought to a balanced state.

Similarly, there are few clearly stated objectives related to composition. Merchantable forest stands are cut and reforested to the same species, often in irregular patterns and intermixed with stands that will never be merchantable or which will be too low in volume and too isolated to ever be managed as part of the productive land base. Very little is done to expand the productive forest land base and 
simplify and consolidate stand areas by treating such areas so as to incorporate them with the adjacent cut area.

Although Alberta has done a lot through the delineation of a green area and through its resource planning programs to secure its forest land base, there is still a potential threat to the security of the forest land base. Because all of Alberta's forest lands are open to public use and are managed under the concept of multiple use, there is the danger that productive forest land will be looked at as a large general commons, from which unlimited small withdrawals can be made. Over time, numerous specific losses could accumulate to the point where they exceed the modest withdrawal provisions that have been made for them (generally $2 \%$ of the land base). There is the companion danger that, without withdrawal, other land use considerations could impose harvesting constraints that drive up wood costs to the point where much of the allowable annual cut will not be economically available.

Finally, it should be noted that in spite of a few existing shortcomings, the Alberta vision has made provision to go beyond the concept of sustained yield to the concept of increased yield. Alberta's forest management agreements contain incentives for intensive forest management by providing secure tenure. They also provide that where a forest management agreement holder increases forest productivity through intensive forest management programs (such as spacing, fertilization, genetics or drainage), the allowable annual cut will be increased accordingly and the additional timber will be free of timber dues.

\section{Sustained Yield in Alberta - What is the Reality?}

\section{Sustained Yield}

All of Alberta's forest management areas are being successfully managed for sustained yield as required by law. The sustained yield vision as described earlier, is being realized. Most of the forest management units managed by the Forest Service are being successfully managed to comply with the sustained yield concepts already described. However, in addition to the conceptual deficiencies already described, there are serious implementation problems facing Alberta's foresters.

Through its integrated resource planning program and its green area policy, Alberta has been a leader in securing a defined land base for forest management. However, there are still serious land use problems which threaten the security of the forest land base and are a threat to the ability of the province to sustain the yield of timber from its managed forests. Energy and mineral resource exploration and development is allowed on forest land. These activities are carefully regulated to minimize damage to the forest resource, and compensation for timber loss is paid to the forest manager. Nevertheless, where such activities reach a very high level, as in the case of concentrated coal development in the foothills, they could reduce the forest land base beyond the point where replacement wood can be purchased under the compensation program. They therefore pose a threat to sustained yield. Similarly, unresolved native land claims pose a potential threat to some areas in northern Alberta.

Perhaps more serious than any of these, however, is the continuing demand for more and more wilderness. Such demands often ignore the fact that there are huge areas of forest wilderness in Alberta that are virtually unused. While the wilderness areas in Banff, Jasper and Willmore get some use, the vast wilderness back country in Wood Buffalo
National Park is virtually unused. A few dozen tourists canoe through the Park on the Peace River each summer, and that's it. However, unless the forest industry can do a better job of demonstrating to the average citizen that there will be better family recreational opportunities in managed forests than in pristine wilderness, the unrelenting pressure of the environmental lobby may lead to the withdrawal of more and more forest land for wilderness, or pseudo-wilderness, in the form of wildland recreation areas.

\section{Forest Protection}

Alberta has developed an excellent forest protection program, particularly in forest fire control. Fire loss has been held within prescribed limits in all forest management areas, without exception. In forest management units outside forest management areas, fire loss has been held within prescribed limits in all units within the past five years. This is a major accomplishment, for which the highly skilled staff of the Alberta Forest Service deserve great credit, as does the Alberta Government for its strong financial support. By maintaining a complete detection system of manned towers and lightning detectors, by establishing an aggressive initial attack system, with prepositioned helicopter attack crews, supplemented with 18 fire bombing aircraft, and a large complement of well trained fire fighting crews, Alberta is meeting its forest protection mandate.

Although its capability to fight insect infestations is less well developed, the Alberta Forest Service did an excellent job of controlling the mountain pine beetle infestations from 1983 to 1987 . Some experience was obtained with a small spruce budworm spray program north of Spirit River this year. Fortunately, Alberta has not faced any major budworm outbreaks. The most serious insect problem in Alberta in recent years has been the forest tent caterpillar outbreak which has defoliated vast areas of aspen in the province over the past five years. There has been no attempt to control this infestation, which is now beginning to cause mortality in aspen stands that have been repeatedly defoliated.

\section{Estimating Allowable Cut}

Allowable annual cuts have been carefully established in Alberta in recent years. With the completion of the Phase III forest inventory in the early 1980's, virtually all allowable cuts are now based on reliable age and volume information by species groups, with very detailed cover type mapping and accurate stand areas. However, site information is still of questionable accuracy, and there is still a need for more specific growth and yield information to improve the accuracy of assumptions on growth and yield in currently forested stands.

The Alberta Forest Service started two important growth and yield data collection programs in regenerated stands in 1983 which have already provided some useful information. In addition, more permanent sample plots are being established by the Timber Management Branch to help bridge the gap between regeneration less than 15 years old and the previous permanent sample plots which were usually established in stands over 50 years old. Nevertheless, there is currently very little information on growth and yield in reforested stands, except for the Weldwood forest management area at Hinton, where a very farsighted permanent sample plot program is beginning to yield valuable information on growth and mortality in stands reforested in the 1950's. 
On the forest management units, the Alberta Forest Service establishes yield curves for fully stocked stands of both coniferous and deciduous species based on the Phase III forest inventory. The yield curves are derived by summing the specified growing stock and areas within each age class and then calculating the average volume per hectare in each age class. Separate conifer and deciduous yield curves are developed for each region. These fully stocked yield curves are used in determining stand merchantability as well as for projecting second rotation allowable cuts.

The age class structure of each forest management unit is analyzed separately for the coniferous and deciduous species groups.

A number of different harvest level volumes are calculated using the following techniques:

Timber RAM - a linear programming optimization model which has been adopted to simulate the two pass (cut and leave blocks) harvest system used in Alberta. The model normally projects harvest levels for two rotations.

Area-Volume Check - An area-volume allotment (check) procedure is run which normally assumes that the total operating area is harvested during the planned rotation and that a constant flow of annual harvest volume will be maintained for one entire rotation. The AAC produced by this method is used as the "seed" for Timber RAM. Projections are normally run for the second rotation based on the final age-class distribution at the end of the first rotation.

Long Range Sustained Yield Average - The theoretical harvest level for a fully regulated forest where the average volume per hectare at rotation is applied to each hectare at rotation:

$$
\frac{\text { Land Base Area }}{\text { Rotation Period }} \times \underset{\text { Rotation }}{\text { Average Yield at }}=\text { LRSYA }
$$

This value gives an indication of the long-term productivity of the forest management unit or area based on the assumption that all stands are harvested and are fully restocked and that growth at least equals the Phase III fully stocked yield curves for the appropriate species group and region.

Current ACC - The existing allowable cut for the unit is also considered. Frequently, these are Von Mantel cuts derived from old inventory information, and may be quite inaccurate.

The following Figure 1 illustrates how the harvest levels derived from these various calculations are displayed.

These displays are examined for each unit in the context of the age class structure, timber quality and location of the unit and a decision is made on an appropriate allowable annual cut. As stated earlier, except in rare circumstances, an allowable cut is chosen that is sustainable for the entire rotation and which does not require a major reduction for the second rotation. In the example shown in Figure 1, an allowable annual cut close to the LRSYA would probably be selected, unless the old age classes were in very poor condition.

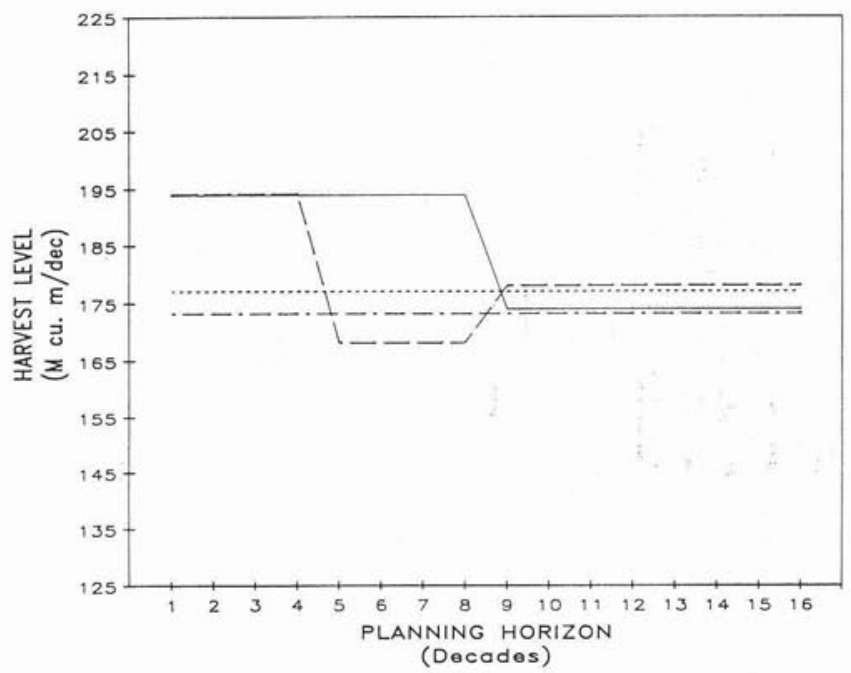

Figure 1. Forest management unit ' $X$ '. Harvest level graph net conifer land base. - AN check, - timber RAM, $\cdots$. LRSYA, - - - current A.A.C.

All gross allowable annual cuts are reduced before establishing the final net allowable cuts to allow for the following factors:

Land Status - all stands not designated for timber harvest in land use plans, and all land areas designated for other uses are excluded. This includes lands in grazing reserves, parks, wilderness areas, protection forest, ecological reserves and natural areas as well as patented lands. All stands on slopes exceeding $45 \%$ are excluded.

Merchantability - all stands are excluded that do not meet and are not projected to meet the minimum volume of $50 \mathrm{~m}^{3}$ per hectare in trees over $15 \mathrm{~cm}$ on the stump to an $11-\mathrm{cm}$ top diameter. In addition, subjective deletions are made for marginal stands that are remote or isolated or which contain a preponderance of unmerchantable small wood even though they meet the basic merchantability definition.

Ground Rules Deletions - All areas contained within non-operable areas under the ground rules are deleted. Examples are stream side reserve areas, lake buffers, road buffers, critical wildlife areas, proposed recreation or natural areas and other reserved land areas. These deletions are identified from the land use planning process and from a referral process in the Department of Forestry, Lands and Wildlife.

Fire Loss - A reduction is made based on the historical average annual loss of productive and potentially productive area within each area of the 10 forests.

Cull Reduction - Cull factors are developed in each volume sample region for each major species and height category and the gross merchantable volume is reduced accordingly to a net volume figure.

In view of the above, what are the weaknesses in Alberta's process to determine allowable cuts? As explained earlier, there is a relatively low priority given to reducing ageclass discrepancies, either through cut control or through specified silvicultural programs. In some cases, the allowable cut will not be sustainable in the second rotation if 
measures are not taken now to improve productivity either by accelerating growth in regenerated stands or through measures to add to the productive land base (drainage, reclamation of stagnant, unmerchantable stands, etc).

There are some more basic problems, however. In the Phase III forest inventory, hardwood species differentiation is inaccurate, and since aspen is preferred to balsam poplar, there is a real risk of running short of aspen while uncut balsam poplar accumulates and takes up valuable productive land base.

A more serious problem exists, however. The information on which the yield curves is based is questionable because of inadequate age, growth and yield information in the Phase III inventory. Compounding this problem is the fact that the growth and yield information for reforested stands is inadequate. Since the second rotation will be based almost entirely on growth from reforested stands, as opposed to stands of fire-origin that we now have, it is essential to have detailed and accurate data. A complete system of permanent sample plots should be required on all forest management areas without delay.

Information now available indicates that the growth and yield of lodgepole pine and aspen on cutovers in Alberta will substantially exceed those which occurred in extremely dense stands of fire-origin. Spruce also has exhibited extremely high growth rates where it has been free of competition from grass and brush. However its growth has often been very slow or terminating where competition is heavy. In consequence, the projections now being made for the second rotation, based on yield curves from natural stands of fire-origin, are probably conservative for pine and optimistic for spruce unless measures are taken to insure that spruce seedlings are "free to grow".

Where unexpected timber losses occur, Alberta has very strong timber salvage policies, which penalize aggressively for failure to salvage and provide incentives by way of reforestation and timber dues savings to encourage salvage. The prompt salvage of windthrown, infested or fire-killed timber has been very important in maintaining allowable cuts in Alberta. Allowable annual cuts are strictly enforced, within five-year production control periods, as explained earlier.

\section{Timber Harvesting}

Timber harvesting operations must be conducted in accordance with approved long-term (full rotation) management plans and shorter-term (two years) annual operating plans. Timber harvesting is strictly regulated and controlled. Operations (every cut block) are regularly inspected and waste is not allowed. Logging roads and landings are carefully supervised and inspected to insure there is not erosion, and that stream crossings are properly made to avoid blockage or siltation. Culvert and bridge installations are checked to insure they are adequate to handle peak flows and allow for free passage of fish. Cut block layout is now highly sophisticated, to include wildlife and scenic (landscape) considerations as well as silvicultural and logging requirements. Within each five-year cut-control period, the allowable cuts cannot be exceeded, and must be at least $80 \%$ utilized. If chronic undercuts persist, the forest management area or quota may be reduced.

\section{Reforestation}

Reforestation is regulated in Alberta, and the regulations are strictly enforced. All areas harvested for commercial timber production must be fully reforested to $80 \%$ stocking by the end of the seventh year after harvest. Initial reforestation treatment must be done within two years of harvest and a complete reforestation survey must be undertaken no later than the end of the seventh year after harvest. Significant penalties are imposed for lateness or non-compliance. All companies, whether operating under quota or forest management agreement, are fully complying with these regulations. Over $95 \%$ of all areas cut since 1966 have been satisfactorily stocked under these regulations. The small percentage $(<5 \%)$ which continue to show as non-stocked either have been retreated and are awaiting survey, or are scheduled for retreatment.

These statistics on reforestation success are not estimates, but come from actual data. Since 1966 all cut blocks have been entered into a computer record when approved for cutting, with data on location, size and cover type. All reforestation treatments and survey results are recorded. If a block is not reforested and surveyed on time, the computer places it on a delinquent list and corrective action is required. The computer keeps recalling the block until the necessary reforestation is done and the block passes a survey as stocked. The block area is then classified as stocked.

In spite of this dedicated effort, Alberta has a serious reforestation problem, which threatens the achievement of sustained yield in many of the northern forest management units where spruce has been cut from the boreal mixed wood forest. Spruce seedlings, successfully established under the reforestation program, are gradually being lost because of intense competition from grass, brush and deciduous species.

The reforestation surveys count a spruce seedling as established once it has grown on site for three years. Losses (mortality) after that time do not show up. Recent surveys have shown that approximately one-third of the spruce seedlings are lost after three years, and after the required reforestation survey. The Forest Service is very aware of this problem, and measures are now being taken to strengthen the reforestation requirements to incorporate mandatory later surveys and include minimum tree size and growth requirements to insure that seedlings will be large and vigorous enough to survive and over-top grass and herbaceous competition. These measures will impose very heavy additional costs on the industry.

It is also evident that much larger spruce seedlings with much more root mass, should be planted to overcome the brush problem and meet the proposed new standards. This is creating another problem, a shortage of nursery capacity. Whereas the Pine Ridge nursery was producing up to 30 million seedlings a year, its capacity is being cut back to 20 million as larger cavities and wider bed spacings are used to grow larger, more vigorous seedlings. This reduction has accelerated the need for another major greenhouse facility to grow containers. More bare root seedling beds will also have to be added, probably at Pine Ridge.

There is a low cost tool, available to help foresters attack the problem of brush and grass competition. If the area within a one-metre radius of all spruce seedlings could be sprayed with glyphosate (such as Round-Up) at the time of the sevenyear survey, this problem would be greatly reduced at 
minimum cost. However the Alberta Government, at least at this time, will not allow anything but experimental use of glyphosate in forested areas, in spite of its quick biodegradability, low toxicity to animal life, and extensive use in agricultural and urban areas.

\section{Conclusion}

A dedicated and successful effort is being made to realize the sustained yield vision in Alberta's forests. All is not perfect, and there are some substantial problems to be overcome. The most important of these problems are being tackled vigorously, to the limit of the resources available.

More funding is urgently needed to meet the high cost of cleaning and tending young seedlings, particularly if governments refuse to allow the use of herbicides where they are the most cost-effective means available to overcome these problems. There is also an urgent need to begin systematic collection of growth and yield information, particularly in reforested stands, as it is these stands that will form the second forest and determine the yield in the second rotation.

\section{Acknowledgements}

The assistance of the Alberta Forest Service, Timber Management Branch is gratefully acknowledged. Evelynne Wrangler and her staff were particularly helpful in providing detailed explanations and examples, including Figure 1, illustrating the methodology and procedures used in establishing allowable annual cuts for forest management units in Alberta.

\section{References}

Davis, K.P. 1966. Forest Management: Regulation and Valuation. 2nd ed. Yale University.

Ford-Roberston, F.C. 1971. Terminology of Forest Science, Technology Practice and Products. Soc. of Am. For., Joint FAO/IUFRO Comm. on For. Bib. \& Term.: 267.

Government of Province of Alberta,

1971. Forests Act.

1973. Forests Act, Timber Management Regulations.

1989. Forests Act, Forest Management Agreement, ANC Timber Ltd.

1977. Forests Act, Forest Management Agreement, North Canadian Forest Industries Limited.

1988. Forests Act, Forest Management Agreement, Proctor \& Gamble Inc.

1975. Forests Act, Forest Management Agreement, Simpson Timber Co. (Alberta) Ltd.

1988. Forests Act, Forest Management Agreement, Weldwood of Canada Limited, Hinton.

1986. Forests Act, Forest Management Agreement, Weldwood of Canada Limited, Slave Lake

1985. Memorandum of Agreement, Pelican Spruce Mills Ltd.

\title{
Canada's Timber Resources A National Conference
}

\author{
June 3-6, 1990, Conference Centre, Victoria, B.C.
}

A broad range of speakers from across Canada will address the current status of Canada's forests, their rate of change and the long run timber supply. Technical sessions will include presentations of case studies and papers describing innovative approaches to growth and yield estimation, forest regulation, integrated forest resource management and timber supply forecasting.

For information on registration, conference program, poster session, accommodation and travel, contact:
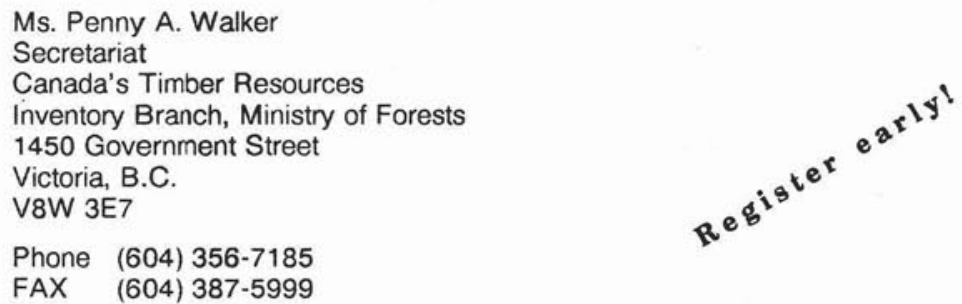

Sponsored by: Forestry Canada and B.C. Ministry of Forests

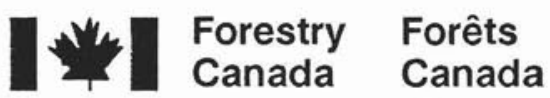

